\title{
Disturbed inflammatory/anti-inflammatory milieu and activation of Primary Phase Reactants may underlie Development and Recurrence of First trimester Pregnancy Loss.
}

'Mohamad F. Al-Sherbeny MD \& ${ }^{2}$ Manal M. Hassaan MD 'Department of Obstetrics \& Gynecology, Faculty of Medicine, Benha University,

${ }^{2}$ Department of Medical Biochemistry, Faculty of Applied Medical Sciences, Oct.6 University

\begin{abstract}
$\underline{\text { Abstract }}$
Objective: Estimation of serum levels of tumor necrosis factor- $\alpha$ (TNF- $\alpha$ ), interleukin (IL-) 6 and 10 and alpha- 1 antitrypsin (AAT) in pregnant women with current pregnancy loss (CPL) and non-pregnant women with history of recurrent PL (RPL) compared versus women with normal pregnancy (NP).

Patients \& Methods: All studied women underwent clinical and vaginal ultrasonographic examination for assurance of inclusion criteria and then gave blood samples for ELISA estimation of studied parameters.

Results: Patients of CPL and RPL groups showed significantly high serum TNF- $\alpha$ and IL-6 levels with significantly lower serum IL-10 levels than women of NP group with significant difference between CPL and RPL groups. Serum AAT levels were significantly lower in CPL group than RPL and NP groups with significantly lower levels in RPL than NP group. High serum TNF- $\alpha$ and low AAT levels showed high positive predictive value (PPV) and sensitivity, respectively, for possibility of presence or recurrence of $\mathrm{PL}$
\end{abstract}

Conclusion: Disturbed serum levels of pro- and anti-inflammatory cytokines could diagnose CPL with high PPV and persistence of their disturbed levels may predispose to RPL. Activation of primary phase reactant system may underlie, accompany or initiate PL, so low serum AAT during 1 st trimester and its persistently low serum levels during interpregnancy intervals could be used as screening test for presence or liability for development of PL.

Keywords: First trimester pregnancy loss, Inflammatory cytokines, Alpha-1 antitrypsin

\section{Introduction}

Recurrent pregnancy loss (RPL), commonly defined as 3 consecutive losses at 10 weeks gestation, affects up to $5 \%$ of couples ${ }^{(1)}$. The medical evaluation of RPL is mainly focused on maternal factors ${ }^{(2)}$. Well-accepted causes include uterine malformation, antiphospholipid syndrome, and parental chromosomal abnormalities; however, up to $75 \%$ of RPL cases is idiopathic ${ }^{(1)}$.

Successful pregnancy relies on the accurate regulation of the maternal-fetal immune system, without enough tolerance in the uterine microenvironment, the mother and fetus could not peacefully coexist ${ }^{(3)}$. Balanced immune responses are required for the maintenance of successful pregnancy and innate immune disturbances may be responsible for some adverse pregnancy outcomes including recurrent spontaneous abortion ${ }^{(4)}$.

Regulatory $\mathrm{T}$ cells and $\mathrm{T}$ helper 17 cells are two distinct subsets of CD4+ T cells, which are mutually antagonistic in the immune response, but their dysregulation may play a role in pathogenesis of unexplained 
recurrent spontaneous abortion ${ }^{(5)}$. Moreover, limited information is available on the balance state of pro- and anti-inflammatory cytokines in patients with recurrent implantation failure ${ }^{(6)}$.

Alpha-1 antitrypsin (AAT) is a glycoprotein, serine protease inhibitor that is abundant in plasma (7). AAT is the prototypical protease inhibitor from the serine protease inhibitor superfamily that protects tissues from proteolytic damage ${ }^{(8)}$. AAT exhibits immunomodulatory properties in several T-celldependent immune pathologies ${ }^{(9)}$. AAT molecule is predominantly produced in the liver ${ }^{(10)}$, but was produced locally by human amniotic epithelial cells (11). AAT rises during acute phase responses and healthy pregnancies ${ }^{(9)}$. AAT in the amnion may function as a protective shield at inflammatory sites, and it loses its inhibitory activity in cases with preterm premature rupture of the membranes possibly by oxidation ${ }^{(12)}$.

\section{Objectives}

Evaluation of serum levels of tumor necrosis factor- $\alpha$ (TNF- $\alpha$ ), interleukin (IL-) 6 and 10 and alpha- 1 antitrypsin (AAT) in pregnant women with current pregnancy loss (CPL) and non-pregnant women with history of RPL compared versus women with normal pregnancy (NP).

\section{Setting}

University hospital, Benha, Egypt

\section{Design}

Prospective comparative double-blinded study

\section{Patients \& Methods}

The current study was conducted at Obstetrics \& Gynecology and Clinical Pathology departments since Jan 2015 till Aug 2016. The study protocol was approved by the Local Ethical Committee. Patients were enrolled in the study after singing a written fully informed consent for study precipitation and giving required blood samples.

The study included pregnant women with history of 1 st trimester RPL, had no living children and diagnosed as having current spontaneous abortion (CPL group), pregnant women of cross-matched gestational age (GA), had no history of RPL and had at least one living child (NP group) and women with history of 1st trimester RPL, had no living children but had no current pregnancy at time of enrolment in the study (RPL group).

All women suspected to fulfill the inclusion criteria had full clinical examination for determination of demographic data, previous obstetric history, data of the current pregnancy and then underwent transvaginal ultrasonography (TVU) to ascertain the inclusion criteria for each group, determination of the exact GA and presence of normal fetal cardiac activity for women of NP group.

Exclusion criteria included missed inclusion criterion, presence multiple gestation pregnancy, presence of anatomical abnormalities or autoimmune diseases inducing RPL, or failure to detect pregnancy sac, determination of GA on TVU.

\section{Blood sampling}

All study participants gave $5 \mathrm{ml}$ blood sample that was withdrawn under complete aseptic conditions, allowed to clot and then centrifuged at $3000 \mathrm{rpm}$ for 10 minutes to separate serum that was collected in sterile Eppindorff tube and stores at $-80 \mathrm{oC}$ till be assayed. Blood samples were collected and numbered by an assistant who was blinded about diagnosis.

\section{Laboratory investigations}

Serum levels of IL 10, IL-6 and TNF- $\alpha$ were measured using enzyme linked immunosorbent assay (ELISA) kits according to the manufacturer's instructions and were read using a 96 well microplate ELISA reader (Dynatech MR 7000).

1. Serum IL-10 was measured using an ELISA kit from Milenia ${ }^{R}$, DPC Biermann, Bad Nauheim; Germany (13).

2. Serum IL-6 (14) and TNF- $\alpha$ (15) levels were measured with an ELISA kit from Pelikine ${ }^{\mathrm{TM}}$ Inc., Concord, USA.

3. Serum AAT was measured with an ELISA kit from Abcam, USA (16).

\section{Statistical analysis}

Obtained data were presented as mean $\pm \mathrm{SD}$, ranges, numbers and precentages. Results were analyzed using One-way ANOVA with post-hoc Tukey HSD Test and Chi-square test (X2 test). Sensitivity \& positive predictive value (PPV; 1-specificity) of estimated parameters as predictors were evaluated using the receiver operating characteristic (ROC) curve analysis judged by the area under the curve (AUC) compared versus the null hypothesis that $\mathrm{AUC}=0.05$. Regression analysis (Stepwise method) was used for stratification of studied parameters as specific predictors. Statistical analysis was conducted using the SPSS (Version 15, 2006) for Windows statistical package. P value $<0.05$ was considered statistically significant. 


\section{Results}

The study included 90 women; 30 in each group. Patients' enrolment data showed non-significant difference between the three groups (Table 1).

Table 1: Demographic and clinical data of studied women.

\begin{tabular}{|l|l|c|c|c|}
\hline \multicolumn{2}{|c|}{ Data } & NP group (n=30) & CPL group (n=30) & RPL group (n=30) \\
\hline \multirow{2}{*}{ Age (years) } & Weight $(\mathrm{kg})$ & $26.5 \pm 3.7$ & $26.7 \pm 2.9$ & $27.4 \pm 4.3$ \\
\hline \multirow{3}{*}{ BMI data } & Height $(\mathrm{cm})$ & $16.4 \pm 14.3$ & $74.3 \pm 9.4$ & $76.9 \pm 12.9$ \\
\cline { 2 - 5 } & BMI $(\mathrm{kg} / \mathrm{m} 2)$ & $27.4 \pm 5.1$ & $166 \pm 2.5$ & $166 \pm 3.4$ \\
\hline \multicolumn{2}{|l|}{ Gestational age (weeks) } & $9.9 \pm 1.7$ & $26.7 \pm 3.5$ & $27.9 \pm 4.6$ \\
\hline Gravidity & $3.4 \pm 0.6$ & $10.4 \pm 1.6$ & 0 \\
\hline \multicolumn{2}{|l|}{ Parity } & $2.6 \pm 0.9$ & $2.9 \pm 1$ & $2.8 \pm 0.8$ \\
\hline
\end{tabular}

Data are presented as mean $\pm \mathrm{SD}$; NP group included women with current normal pregnancy; CPL group included women with current spontaneous abortion; RPL group included non-pregnant women with history of recurrent pregnancy loss; BMI: Body mass index; $\mathrm{p}>0.05$ indicates non-significant difference

Pregnant women with CPL or non-pregnant women with previous RPL showed significantly disturbed serum levels of estimated pro-inflammatory and anti-inflammatory cytokines with a more pronounced disturbance in patients of CPL group than women of RPL group. Moreover, serum AAT levels were significantly lower in patients with CPL than patients of other groups with significantly lower levels in patients with past history of RPL (Table 2).

Table 2: Mean serum levels of parameters estimated in studied women.

\begin{tabular}{|c|c|c|c|c|}
\hline \multicolumn{2}{|c|}{ Group Parameter } & \multirow{2}{*}{$\begin{array}{c}\text { NP group }(\mathbf{n}=\mathbf{3 0}) \\
3.18 \pm 1.25\end{array}$} & \multirow{2}{*}{$\begin{array}{c}\text { CPL group }(\mathbf{n}=\mathbf{3 0}) \\
7.91 \pm 4.17\end{array}$} & \multirow{2}{*}{$\begin{array}{c}\text { RPL group }(\mathbf{n}=\mathbf{3 0}) \\
5.11 \pm 3.17\end{array}$} \\
\hline \multirow{3}{*}{ Serum TNF- $\alpha$} & Level & & & \\
\hline & $\mathrm{P} 1$ & & $=0.001$ & 0.048 \\
\hline & $\mathrm{P} 2$ & & & 0.0022 \\
\hline \multirow{3}{*}{ Serum IL-6 } & Level & $16.9 \pm 4.12$ & $23.61 \pm 6$ & $20.43 \pm 5$ \\
\hline & $\mathrm{P} 1$ & & $=0.001$ & 0.024 \\
\hline & $\mathrm{P} 2$ & & & 0.047 \\
\hline \multirow{3}{*}{ Serum IL-10 } & Level & $27.25 \pm 10.1$ & $17.16 \pm 4.52$ & $21.81 \pm 6.69$ \\
\hline & P1 & & $=0.001$ & 0.016 \\
\hline & $\mathrm{P} 2$ & & & 0.046 \\
\hline \multirow{3}{*}{ Serum AAT } & Level & $2.17 \pm 0.5$ & $1.75 \pm 0.35$ & $2.08 \pm 0.51$ \\
\hline & $\mathrm{P} 1$ & & $=0.0019$ & 0.682 \\
\hline & $\mathrm{P} 2$ & & & 0.021 \\
\hline
\end{tabular}

Data are presented as mean $\pm \mathrm{SD}$; NP group included women with current normal pregnancy; CPL group included women with current spontaneous abortion; RPL group included non-pregnant women with history of recurrent pregnancy loss; TNF- $\alpha$ : Tumor necrosis factor- $\alpha$; IL-6: Interleukin-6; IL-10: Interleukin-10; AAT: $\alpha 1$ antitrypsin; P1 indicates significance versus NP group; P2 indicates significance versus SA group; $p<0.05$ indicates significant difference; $\mathrm{p}>0.05$ indicates non-significant difference

Statistical analysis using ROC curve for estimated serum parameters for differentiation between studied women defined low serum AAT as a significant sensitive parameter for differentiation between women with current RPL out of women had normal pregnancy (Fig. 1) and non-pregnant women with past history of RPL (Fig. 2) and for differentiation between women with past-history of RPL and normal pregnant women (Fig. 3); so could be used as screening test for presence or liability for development of RPL. On the other hand, high serum levels of TNF- $\alpha$ could differentiate between women with presence or liability to have RPL out of women with normal pregnancy with high positive predictive value, (Tables 3 ). 
Table 3: ROC curve analysis for estimated serum parameters as predictors for pregnancy loss as current or recurrent among studied women.

\begin{tabular}{|l|c|c|c|c|c|c|c|c|c|}
\hline \multicolumn{1}{|c|}{ Purpose } & \multicolumn{3}{|c|}{ Prediction of current PL } & \multicolumn{3}{c|}{ Prediction of RPL } & \multicolumn{3}{c|}{ Prediction for liability for } \\
RPL
\end{tabular}

AUC: Area under curve; CI: Confidence interval; TNF- $\alpha$ : Tumor necrosis factor- $\alpha$; IL-6: Interleukin-6; IL-10: Interleukin-10; AAT: $\alpha 1$ antitrypsin; $\mathrm{p}<0.05$ indicates significant difference; $\mathrm{p}>0.05$ indicates non-significant difference

Regression analysis of estimated parameters for prediction of CPL or liability developing RPL defined serum TNF- $\alpha$ as a specific predictor with persistent significance through the conducted analytical models and serum AAT as a sensitive predictor with persistent significance through the conducted analytical models (Table 4).

Table 4: Regression analysis for estimated serum parameters as predictors for pregnancy loss as current or recurrent among studied women.

\begin{tabular}{|c|c|c|c|c|c|c|c|c|}
\hline \multirow{2}{*}{$\begin{array}{l}\text { Statistical } \\
\text { model } \\
\text { Parameter }\end{array}$} & \multicolumn{2}{|c|}{ Model 1} & \multicolumn{2}{|c|}{ Model 2} & \multicolumn{2}{|c|}{ Model 3} & \multicolumn{2}{|c|}{ Model 4} \\
\hline & $\beta$ & $\mathrm{P}$ & $\beta$ & $\mathrm{P}$ & $\beta$ & $\mathrm{P}$ & $\beta$ & $\mathrm{P}$ \\
\hline Serum TNF- $\alpha$ & 0.400 & 0.0009 & 0.477 & 0.0007 & 0.520 & 0.0007 & 0.615 & 0.0004 \\
\hline Serum AAT & -0340 & 0.0008 & -0.389 & 0.0008 & -0.435 & 0.0007 & & \\
\hline Serum IL-10 & -0.242 & 0.004 & -0.267 & 0.003 & & & & \\
\hline Serum IL-6 & 0.226 & 0.014 & & & & & & \\
\hline
\end{tabular}

$\beta$ : Standardized coefficient; TNF- $\alpha$ : Tumor necrosis factor- $\alpha$; IL-6: Interleukin-6; IL-10: Interleukin-10; AAT: $\alpha 1$ antitrypsin; $p<0.05$ indicates significant difference; $p>0.05$ indicates non-significant difference.

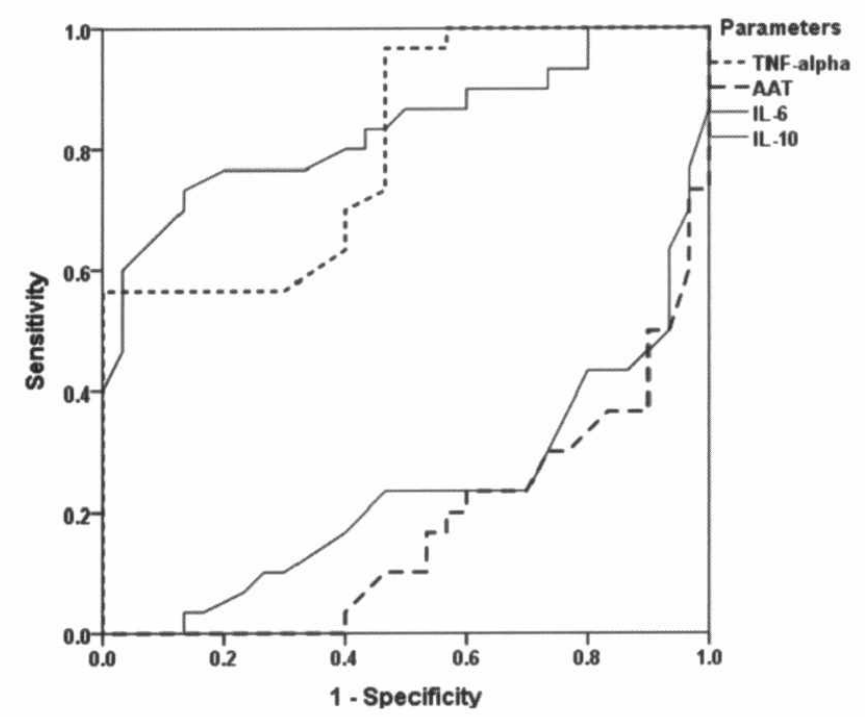

Fig. (1): ROC curve analysis of studied parameters for differentiation between women with NP and CPL

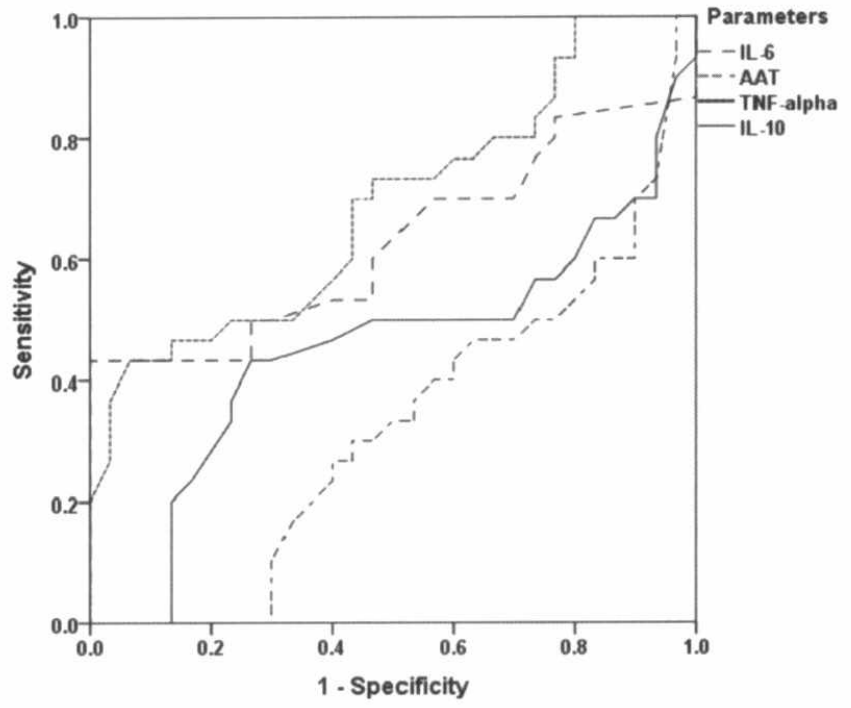

Fig. (2): ROC curve analysis of studied parameters for differentiation between women with NP and RPL 


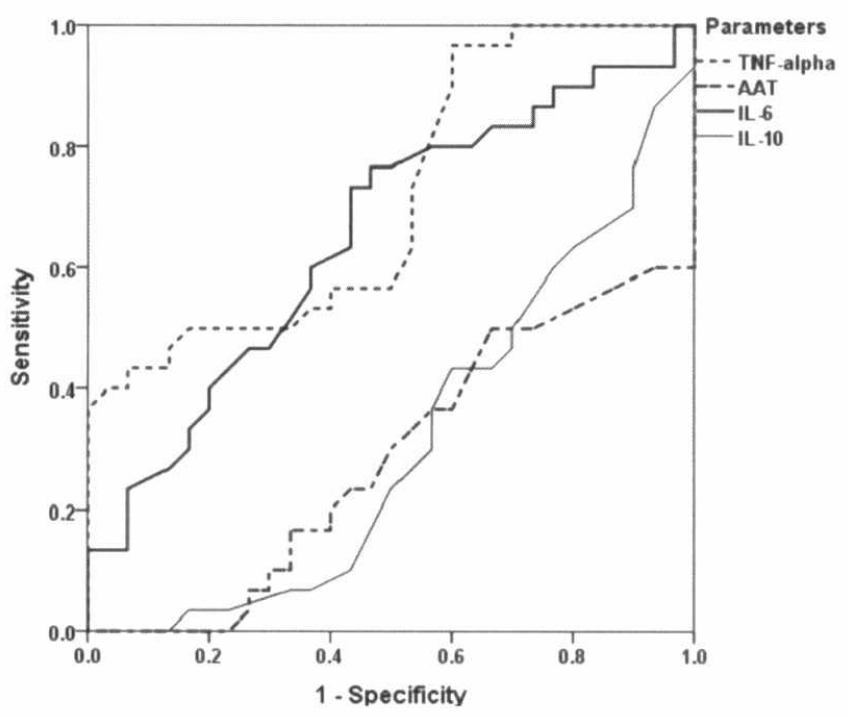

Fig. (3): ROC curve analysis of studied parameters for differentiation between women with RPL and CPL

\section{Discussion}

Patients with current pregnancy loss (CPL) or past history of recurrent PL (RPL) showed significantly high serum TNF- $\alpha$ and IL-6 levels with significantly lower serum IL-10 levels than normal pregnant (NP) women with significant difference between women of both CPL and RPL groups. These findings spot light on a possible role for disturbed immune milieu in pathogenesis of PL and persistent disturbances may underlie the phenomenon of recurrence.

In line with these data Liang et al., ${ }^{(6)}$ found the ratios of pro-inflammatory and anti-inflammatory cytokines IL-6/IL-10 and TNF- $\alpha /$ TGF- $\beta 1$ were higher in women had recurrent implantation failure (RIF) after IVF/ intracytoplasmic sperm injection-embryo transfer, thus suggesting a shift toward a pro-inflammatory state in peripheral blood of the patients with RIF. Galgani et al. (17) documented that women with recurrent miscarriage (RM) and RIF showed an increase of circulating pro-inflammatory cytokines, altered endometrial $\mathrm{T}$ lymphocytes subsets, and signs of endometrial endoplasmic reticulum stress. Also, Ozkan et al. (18) detected a significantly high TNF- $\alpha / \mathrm{IL}-10$, TNF- $\alpha /$ IL-4 and concluded that increased Th1/Th2 cytokine ratios in RPL cases pointed to suppression of antiinflammatory process that might play an important role in the pathogenesis of idiopathic RPL. Recently, Zhang et al. (19) found baseline TNF- $\alpha$ levels were higher in patients with recurrent spontaneous abortion than in controls.

Moreover, high serum TNF- $\alpha$ showed high AUC in ROC curve analysis for prediction of presence or possibility of recurrence of PL, thus indicating a high positive predictive value for high serum TNF- $\alpha$ for a possibility of PL in a woman had recurrent attack. Similarly, Lee et al. ${ }^{(20)}$ found TNF- $\alpha(+)$ Thl cells and Th1/Th2 cell ratio were highly specific for RPL with $\mathrm{AUC}=0.681$ and 0.660 , respectively.

In support of the role of disturbed immune milieu in pathogenesis and/or recurrence of PL, Talukdar et al. (21) detected significantly decreased percentage of Thl cells with significantly decreased levels of IFN- $\gamma$ and TNF- $\alpha$ in the culture supernatant of peripheral blood mononuclear cell (PBMC) from RPL women and treated in vitro with CoQ10 than in untreated cells and attributed this effect to the capability of CoQ10 in reducing oxidative stress by decreasing reactive oxygen species production. Also, Ota et al. (22) experimentally detected significantly decreased Toll-like receptor-4 (TLR4) expression on natural killer (NK) cells and significantly reduced production of TNF- $\alpha$ and IFN- $\gamma$ on incubation of NK cells of RPL women with di-hydroxy vitamin D3 through interference with nuclear factor- $\kappa \mathrm{B}$. Clinically, Ohams et al. ${ }^{(23)}$ found administration of blockers of phosphodiesterase type 5 or TNF- $\alpha$ blockers before conception seems to be a promising future therapy of immune-dependent RM. Recently, Nasiri \& Rasti (24) and Rasti et al., ${ }^{(25)}$ indicated that polymorphisms of cytotoxic T-lymphocyte-associated protein 4 and IL-6 genes ${ }^{(24)}$ and promoter polymorphism $(-634 \mathrm{C} / \mathrm{G})$ of the IL-6 gene ${ }^{(25)}$ are likely to influence the individual susceptibility to RPL.

Serum levels of AAT, a primary phase reactant with immunomodulatory properties ${ }^{(9)}$, were significantly lower in patients with CPL than NP women and non-pregnant women with RPL. Moreover, serum AAT levels estimated in women of RPL group were significantly lower levels than women of NP group. These findings indicated a role of AAT in maintenance of normal immune balance in uterine microenvironment and a possible role for disturbed AAT level in induction and/or recurrence of pregnancy-related disorders. In support of this assumption, statistical analyses defined low serum AAT as a significant sensitive parameter for differentiation between women with current or previous RPL among pregnant women; so could be used as screening test for presence of or liability for development of RPL.

The reported data and provided assumptions go in hand with previous studies evaluated a possible role for AAT in pathogenesis of pregnancy-related disorders, where Twina et al. ${ }^{(26)}$ found AAT levels were about 2 fold lower in the pre-eclampsia (PE) women compared to 
healthy women and correlated with protease inhibitory capacity and Feng et al. ${ }^{(27)}$ reported that the peripheral AAT content was the highest in the normal full-term pregnancy, moderate in early-onset $\mathrm{PE}$, and lowest in late-onset LS-PE women. Madar et al. ${ }^{(28)}$ found AAT levels were lower in both recurrent and sporadic SA patients compared with healthy pregnancies and reduced AAT levels correlated with elevated proinflammatory cytokines. Hsu et al. ${ }^{(29)}$ reported that immunoassays in serum samples of women with severe PE showed that serum AAT, $\alpha 1$-microglobulin, and clusterin levels of were significantly higher than in normal pregnant women.

Recently, Hsu et al. ${ }^{(30)}$ reported that five proteins including AAT may be involved in the pathogenesis of amniotic fluid of Edwards Syndrome. Also, Kononikhin et al. ${ }^{(31)}$ studied a total of 1786 peptides in urine of 30 women with mild to severe PE and identified AAT, collagen $\alpha-1$ (I) and (III) chains, and uromodulin as peptides that can potentially serve as early indicators of PE. Moreover, Feng et al. ${ }^{(32)}$ suggested that exogenous AAT injection increases the antioxidants and suppresses oxidative stress, and subsequent prevention of PE development through inactivation of signal transducer and activator of transcription $1 / \mathrm{p} 38$ signaling.

\section{Discussion}

High serum pro-inflammatory with low serum antiinflammatory cytokines levels could diagnose current pregnancy loss with high PPV and persistence of their disturbed levels may predispose to RPL. Activation of primary phase reactant system may underlie, accompany or initiate PL, so low serum AAT during 1st trimester and its persistently low serum levels during inter-pregnancy intervals could be used as screening test for presence or liability for development of PL.

\section{References}

1. Kaiser J, Branch DW. Recurrent Pregnancy Loss: Generally Accepted Causes and Their Management. Clin Obstet Gynecol. 2016; 59(3):464-473.

2. Amin-Beidokhti M, Mirfakhraie R, Zare-Karizi S, Karamoddin F: The role of parental microRNA alleles in recurrent pregnancy loss: an association study. Reprod Biomed Online. 2017; 34(3):325-330.

3. $\mathrm{Hu} \mathbf{X H}$, Tang MX, Mor G, Liao AH. Tim-3: Expression on immune cells and roles at the maternalfetal interface. J Reprod Immunol. 2016; 118:92-99.

4. Triggianese P, Perricone C, Chimenti MS, De Carolis
C, Perricone R. Innate Immune System at the MaternalFetal Interface: Mechanisms of Disease and Targets of Therapy in Pregnancy Syndromes. Am J Reprod Immunol. 2016;76(4):245-257.

5. Zhu L, Chen H, Liu M, Yuan Y, Wang Z, Chen Y et al. Treg/Th17 Cell Imbalance and IL-6 Profile in Patients With Unexplained Recurrent Spontaneous Abortion. Reprod Sci Reprod Sci. 2017; 24(6): 882-890.

6. Liang PY, Diao LH, Huang CY, Lian RC, Chen X, Li GG et al. The pro-inflammatory and anti-inflammatory cytokine profile in peripheral blood of women with recurrent implantation failure. Reprod Biomed Online. 2015; 31(6):823-826.

7. Huangfu C, Zhang J, Ma Y, Jia J, Lv M, Zhao X et al. New process for purifying high purity $\alpha 1$-antitrypsin from Cohn Fraction IV by chromatography: A promising method for the better utilization of plasma. J Chromatogr B Analyt Technol Biomed Life Sci. 2017; 1046:156-164.

8. Henao MP, Craig TJ. Understanding alpha-1 antitrypsin deficiency: A review with an allergist's outlook. Allergy Asthma Proc. 2017; 38(2):98-107.

9. Guttman O, Freixo-Lima GS, Kaner Z, Lior Y, Rider $\mathrm{P}$, Lewis EC. Context-Specific and Immune CellDependent Antitumor Activities of al-Antitrypsin. Front Immunol. 2016; 7:559.

10. Zemel R, Bachmetov L, Ad-El D, Abraham A, TurKaspa R. Expression of liver-specific markers in naïve adipose-derived mesenchymal stem cells. Liver Int. 2009; 29(9):1326-1337.

11. Takashima S, Ise H, Zhao P, Akaike T, Nikaido T. Human amniotic epithelial cells possess hepatocytelike characteristics and functions. Cell Struct Funct. 2004; 29(3):73-84.

12. Izumi-Yoneda N, Toda A, Okabe M, Koike C, Takashima S, Yoshida $\mathrm{T}$ et al. Alpha 1 antitrypsin activity is decreased in human amnion in premature rupture of the fetal membranes. Mol Hum Reprod. 2009;15(1):49-57.

13. Poll T. IL-10 release during endotoxaemia in chimpanzees: role of platelet-activating factor and IL6. Scand. J Immunol. 1996; 43: 122

14. Gaines-Das RE, Poole S. The international standard for interleukin-6 evaluation in an international collaborative study. J Immunol Methods. 1993; 160: 147-53.

15. De Kossodo S, Houba V, Grau GE. the WHO Collaborative Study Group. Assaying tumor necrosis factor concentrations in human serum. A WHO 
international collaborative study. J Immunol Methods. 1995; 182:107-14.

16. Miyake M, Ross S, Lawton A, Chang M, Dai Y, Mengual L et al. Investigation of CCL18 and A1AT as potential urinary biomarkers for bladder cancer detection. BMC Urol. 2013; 13:42.

17. Galgani M, Insabato L, Calì G, Della Gatta AN, Mirra $\mathrm{P}$, Papaccio $\mathrm{F}$ et al. Regulatory T cells, inflammation, and endoplasmic reticulum stress in women with defective endometrial receptivity. Fertil Steril. 2015; 103(6):1579-86.

18. Ozkan ZS, Deveci D, Simsek M, Ilhan F, Risvanli A, Sapmaz E. What is the impact of SOCS3, IL-35 and IL17 in immune pathogenesis of recurrent pregnancy loss? J Matern Fetal Neonatal Med. 2015; 28(3):324-8.

19. Zhang C, Deng X, Zhang X, Pan Z, Zhao W, Zhang Y et al. Association between Serum TNF- $\alpha$ Levels and Recurrent Spontaneous Miscarriage: A Meta-analysis. Am J Reprod Immunol. 2016; 75(2):86-93.

20. Lee SK, Na BJ, Kim JY, Hur SE, Lee M, Gilman-Sachs A et al. Determination of clinical cellular immune markers in women with recurrent pregnancy loss. Am J Reprod Immunol. 2013; 70(5):398-411.

21. Talukdar A, Sharma KA, Rai R, Deka D, Rao DN. Effect of Coenzyme Q10 on Th1/Th2 Paradigm in Females with Idiopathic Recurrent Pregnancy Loss. Am J Reprod Immunol. 2015; 74(2):169-80.

22. Ota K, Dambaeva S, Kim MW, Han AR, Fukui A, Gilman-Sachs A et al. 1,25-Dihydroxy-vitamin D3 regulates NK-cell cytotoxicity, cytokine secretion, and degranulation in women with recurrent pregnancy losses. Eur J Immunol. 2015; 45(11):3188-99.

23. Ohams M, Jerzak M, Górski A. Effects of sildenafil citrate and etanercept treatment on TNF- $\alpha$ levels in peripheral blood of women with recurrent miscarriage. Ginekol Pol. 2015; 86(7):520-4.

24. Nasiri M, Rasti Z. CTLA-4 and IL-6 gene polymorphisms: Risk factors for recurrent pregnancy loss. Hum Immunol. 2016; 77(12):1271-1274.

25. Rasti Z, Nasiri M, Kohan L. The IL-6 -634C/G polymorphism: a candidate genetic marker for the prediction of idiopathic recurrent pregnancy loss. Int $\mathrm{J}$ Reprod Biomed (Yazd). 2016; 14(2): 103-8.

26. Twina G, Sheiner E, Shahaf G, Yaniv Salem S, Madar $\mathrm{T}$, Baron $\mathrm{J}$ et al. Lower circulation levels and activity of $\alpha-1$ antitrypsin in pregnant women with severe preeclampsia. J Matern Fetal Neonatal Med. 2012; 25(12):2667-70.

27. Feng YL, Zhou CJ, Li XM, Liang XQ. Alpha-1antitrypsin acts as a preeclampsia-related protein: a proteomic study. Gynecol Obstet Invest. 2012; 73(3):252-9.

28. Madar T, Shahaf G, Sheiner E, Brazg J, Levinson J, Yaniv Salem $S$ et al. Low levels of circulating alpha- 1 antitrypsin are associated with spontaneous abortions. J Matern Fetal Neonatal Med. 2013; 26(18):1782-7

29. Hsu TY, Hsieh TT, Yang KD, Tsai CC, Ou CY, Cheng $\mathrm{BH}$ et al. Proteomic profiling reveals $\alpha 1$-antitrypsin, $\alpha 1$-microglobulin, and clusterin as preeclampsiarelated serum proteins in pregnant women. Taiwan $\mathrm{J}$ Obstet Gynecol. 2015; 54(5):499-504.

30. Hsu TY, Lin H, Hung HN, Yang KD, Ou CY, Tsai CC et al. Two-Dimensional Differential Gel Electrophoresis to Identify Protein Biomarkers in Amniotic Fluid of Edwards Syndrome (Trisomy 18) Pregnancies. PLoS One. 2016; 11(1):e0145908.

31. Kononikhin AS, Starodubtseva NL, Bugrova AE. Shirokova VA, Chagovets VV, Indeykina MI et al. An untargeted approach for the analysis of the urine peptidome of women with preeclampsia. J Proteomics. 2016; 149:38-43.

32. Feng Y, Xu J, Zhou Q, Wang R, Liu N, Wu Y et al. Alpha-1 Antitrypsin Prevents the Development of Preeclampsia Through Suppression of Oxidative Stress. Front Physiol. 2016; 7:176. 